\title{
Current practice of adolescent preventive services among paediatric residents in Nigeria
}

\author{
M T Abiodun, FWACP (Paed); A I Omoigberale, FWACP (Paed); M O Ibadin, FMC (Paed) \\ Department of Child Health, University of Benin Teaching Hospital, Benin City, Nigeria
}

Corresponding author: M T Abiodun (biodunmt27@yahoo.com)

\begin{abstract}
Background. There has been a growing recognition of the challenge of Nigerian adolescents' health issues and the need to address it. Adolescent preventive services (APS) constitute an effective mechanism to reduce adolescent morbidities.

Objective. To evaluate the current practice of APS among Nigerian paediatric residents.

Methods. For this cross-sectional survey, we designed an anonymous questionnaire based on Guidelines of APS of the American Medical Association to elicit information on residents' current practice regarding screening adolescents for specific morbidities.

Results. A total of 103 residents participated in the study; nearly $60 \%$ were from federal teaching hospitals. The majority (78.6\%) attended to adolescents at least once a week. In the last month, the adolescent medicine service most commonly provided by respondents was general health guidance (66.7\%). Altogether, less than one-fifth of the residents have recently asked at least two specific questions to screen adolescents for eating disorders, violence, safety issues, depression, substance or sexual abuse. Senior registrars were more likely than registrars to screen adolescents for hypertension $(75.0 \%$ v. $29.1 \%, p=0.032)$, depression $(50.0 \%$ v. $16.5 \%, p=0.043)$ and abuse $(62.5 \%$ v. $22.1 \%, p=0.023)$. Also, residents with $<5$ years in practice were more likely to screen for relationship issues $(p=0.045)$.

Conclusion. The current level of practice of APS is low among paediatric residents in Nigeria. There is a need to restructure their ongoing practice and training to emphasise preventive paediatrics and other issues pertinent to adolescent care.
\end{abstract}

S Afr J Child Health 2016;10(2):108-110. DOI:10.7196/SAJCH.2016.v10i2.717

The provision of adolescent preventive services (APS) is imperative globally among clinicians, especially paediatricians. ${ }^{[1]}$ Adolescents are at a developmental stage that is characterised by experimentation and risk-taking owing to their emerging cognitive abilities and social experiences. ${ }^{[1,2]}$ They are therefore vulnerable to a wide range of morbidities. Besides general health problems, adolescents are often susceptible to violence, substance abuse, and behavioural and reproductive health issues. ${ }^{[2,3]}$ For instance, according to a 2010 UNICEF report, only about one-quarter of adolescents aged 15 19 years in Nigeria have comprehensive knowledge of HIV, and almost half of the females (46.2\%) and about a quarter of the males $(22.1 \%)$ have engaged in sexual intercourse. ${ }^{[4]}$ This knowledge gap can be bridged by general health education and provision of adolescentfriendly services to the populace.$^{[5]}$ Again, the persistently high levels of adolescent morbidity and mortality over recent decades further attest to the need for adolescent-oriented preventive services in our societies. $^{[6,7]}$ Anticipatory guidance and other preventive services should be integrated into routine clinical practice by all clinicians attending to adolescents. This is particularly necessary in developing countries where child welfare clinics are poorly attended and routine health checks have not been absorbed into the health-seeking culture of most families ${ }^{[8]}$ People visit health facilities mainly to seek curative services that could not effectively control prevalent morbidities among adolescents and other age groups in the society. ${ }^{[8]}$ There has been a limited emphasis on adolescent medicine (AM) in Nigeria previously, despite the fact that adolescents constitute about onefifth of the Nigerian population, and one in five African adolescents is a Nigerian. ${ }^{[4]}$ Consequently, there are no Nigerian guidelines on APS. AM services are incorporated into school health programmes, community/preventive paediatrics and other core areas of paediatrics during residency training in Nigeria. ${ }^{[9]}$ Based on the current training curriculum contents, the level of competence in the provision of APS expected of Nigerian paediatrics residents is comparable with that specified in Guidelines of Adolescent Preventive Services (GAPS) of the American Medical Association, ${ }^{[1]}$ recommended for all primary healthcare providers. This study describes the provision of AM services and the current level of practice of APS among Nigerian paediatric residents.

\section{Methods}

The study was carried out from 19 February to 4 March 2013 at the multipurpose hall of Oba Akenzua Complex at the University of Benin Teaching Hospital, Benin City, Nigeria. The participants were resident doctors in paediatrics attending the Intensive Course in Paediatrics of the National Postgraduate Medical College of Nigeria at the venue. Permission was sought from the local organising committee of the revision course. Informed consent was obtained from every study participant.

We conducted a descriptive cross-sectional study. A total of 105 residents out of an estimated 160 paediatric residents attending the revision course took part in the survey. Two residents were later excluded because they had been on leave for the month preceding this study; they were otherwise similar to the other respondents. A self-administered, anonymous questionnaire was designed, comprising the following sections: (i) residents' sociodemographic features and practice settings; (ii) clinical practice pertinent to adolescents; (iii) screening adolescents for specific morbidities in the last month (excerpt of GAPS questionnaire). ${ }^{[1]}$ Open-ended questions enabled respondents to specify any other screening questions asked of adolescents recently. Respondent's training institutions were classified into federal, state and others. Their institutions were simply described by geopolitical zones. Specific names and addresses were not required, in order to ensure confidentiality.

The data were analysed using the SPSS version 20.0 (IBM Corp., USA). Categorised data such as sex, status and geographical zones were presented as proportions. The frequencies for the responses were calculated. Fisher's exact test or Pearson's $\chi^{2}$ was used to compare federal and state residents' practices of APS, and to assess for any significant difference between northern and southern geopolitical zones. A two-sided $p$-value $<0.05$ was considered significant. 


\section{Results}

A total of 103 residents participated in the survey, $68 \%$ and $32 \%$ from southern and northern geopolitical zones, respectively. Nearly $60 \%$ were from the Federal Teaching Hospital while the rest where mainly from state facilities. Over $90 \%$ of them were registrars. The mean (SD) age of the respondents was 32.6 (4.3) years. Further details of participants' characteristics are shown in Table 1. Roughly one-third of the residents attended to adolescents daily, while about $50 \%$ of them met adolescents in their clinical practice weekly (Table 2).

In the last month, the AM services most commonly provided by respondents were general health guidance $(66.7 \%)$ and specific screening for morbidity (51.1\%).

Table 1. Sociodemographic and practice characteristics of the respondents

\begin{tabular}{ll}
\hline Characteristics & $\boldsymbol{n}(\%)$ \\
\hline Sex & \\
Male & $47(45.6)$ \\
Female & $56(54.4)$ \\
Duration of practice (years) & \\
$<5$ & $44(42.7)$ \\
$\geq 5$ & $59(57.3)$ \\
Current status & \\
Registrar & $95(92.2)$ \\
Senior registrar & $8(7.8)$ \\
Current institution of & \\
residency & \\
Federal Teaching Hospital & $61(59.2)$ \\
Federal Medical Centre & $24(23.3)$ \\
State Teaching Hospital/ & $18(17.5)$ \\
others & \\
Geopolitical zones & \\
North-east & $7(6.8)$ \\
North-west & $10(9.7)$ \\
North-central & $16(15.5)$ \\
South-east & $17(16.5)$ \\
South-west & $27(26.2)$ \\
South-south & $26(25.3)$ \\
\end{tabular}

Table 2. Frequency of adolescent patient visits in residents' clinical practice

\begin{tabular}{ll}
\hline Adolescent patient visits & $\boldsymbol{n}(\%)$ \\
\hline Daily & $32(31)$ \\
Weekly & $49(47)$ \\
Every 2 months & $7(6.8)$ \\
Others & $15(14.6)$ \\
Total & $103(100)$
\end{tabular}

Case managements or anticipatory health guidance related to diabetes mellitus, dyslipidaemia, depression and violence were carried out by less than one-fifth of the residents (Table 3). Senior registrars were more likely than registrars to screen adolescents for hypertension $(75.0 \% \mathrm{v}$. $29.1 \%, p=0.032)$ and depression $(50.0 \%$ v. $16.5 \%, p=0.043)$. Duration of medical practice did not influence the number of AM services provided by the respondents.

The practice of screening adolescents for specific morbidities using standard questions was quite low among residents in this survey, although $51.1 \%$ of them initially identified 'specific screening for morbidity' as a part of the AM services they provided in their clinical practice. Altogether, $<20 \%$ of

Table 3. Residents' provision of AM services in the last month

\begin{tabular}{llll}
\hline & \multicolumn{3}{c}{$n(\%)$} \\
\cline { 2 - 4 } AM services & Yes & No & I don’t know \\
\hline Specific screening for morbidity $(n=88)$ & $45(51.1)$ & $43(48.9)$ & $0(0.0)$ \\
Counselling to reduce risk $(n=95)$ & $46(48.4)$ & $49(51.6)$ & $0(0.0)$ \\
Immunisation $(n=90)$ & $17(18.9)$ & $73(81.1)$ & $0(0.0)$ \\
General health guidance $(n=93)$ & $62(66.7)$ & $31(33.3)$ & $0(0.0)$ \\
Hypertension $(n=94)$ & $31(33.0)$ & $62(66.0)$ & $1(1.1)$ \\
Obesity $(n=95)$ & $26(27.4)$ & $68(71.6)$ & $1(1.1)$ \\
Hyperlipidaemia $(n=94)$ & $14(14.9)$ & $79(84.0)$ & $1(1.1)$ \\
Type 2 diabetes mellitus $(n=93)$ & $7(7.5)$ & $85(91.4)$ & $1(1.1)$ \\
Violence $(n=96)$ & $13(13.5)$ & $82(85.4)$ & $1(1.0)$ \\
Depression $(n=93)$ & $18(19.4)$ & $75(80.6)$ & $0(0.0)$
\end{tabular}

Table 4. Screening adolescents for specific morbidities using GAPS questionnaire $(N=103)$

\begin{tabular}{|c|c|c|}
\hline Screening questions for specific morbidities & Yes, $n(\%)$ & No, $n(\%$ \\
\hline \multicolumn{3}{|l|}{ Eating disorder } \\
\hline Are you satisfied with your eating habits? & $14(13.6)$ & $89(86.4)$ \\
\hline Do you spend a lot of time thinking about ways to be slim? & $13(12.6)$ & $90(87.4)$ \\
\hline $\begin{array}{l}\text { Have you tried to lose weight by vomiting, taking laxatives or } \\
\text { starving yourself? }\end{array}$ & $15(14.6)$ & $88(85.4)$ \\
\hline \multicolumn{3}{|l|}{ Violence/safety } \\
\hline Have you ever been in trouble with the law? & $11(10.7)$ & $92(89.3)$ \\
\hline Are you worried about violence or your safety? & $19(18.4)$ & $84(81.6)$ \\
\hline $\begin{array}{l}\text { In the past year, have you carried a gun, knife, club, etc. for } \\
\text { protection? }\end{array}$ & $8(7.8)$ & $95(92.2)$ \\
\hline Do you usually wear a helmet when you ride a bicycle or motorcycle? & $7(6.8)$ & $96(93.2)$ \\
\hline Do you usually wear a seat belt when you ride in a vehicle? & $8(7.8)$ & $95(92.2)$ \\
\hline \multicolumn{3}{|l|}{ Tobacco/alcohol/drugs } \\
\hline Do you ever smoke cigarettes? & $27(26.2)$ & $76(73.8)$ \\
\hline Do any of your close friends ever smoke cigarettes or chew tobacco? & $23(22.3)$ & $80(77.7)$ \\
\hline In the past month, did you get drunk or very high on alcohol? & $19(18.4)$ & $84(81.6)$ \\
\hline Do you ever use marijuana (grass, weed, etc.) or other drugs? & $15(14.6)$ & $88(85.4)$ \\
\hline \multicolumn{3}{|l|}{ Relationship/abuse/bullying } \\
\hline Are you dating someone? & $33(32.0)$ & $70(68.0)$ \\
\hline Have any of your friends ever had sex? & $22(21.4)$ & $81(78.6)$ \\
\hline Have you ever felt pressured by anyone to have sex? & $22(21.4)$ & $81(78.6)$ \\
\hline Have you seen physically, emotionally or sexually abused? & $26(25.2)$ & $77(74.8)$ \\
\hline Have you been bullied in school in the last month? & $25(24.3)$ & $78(75.7)$ \\
\hline
\end{tabular}


the respondents had screened an adolescent for depression in the last month, asking for the presence of some of the following symptoms for $\geq 2$ weeks: low self-esteem and feelings of worthlessness, insomnia or hypersomnia, psychomotor agitation or retardation, and preoccupation with death and/or suicide. Similarly, less than one-fifth of the residents had asked at least two specific questions to screen adolescents for eating disorders, violence, safety issues, substance or sexual abuse in the last month.

Table 4 summarises residents' responses to the use of standard questions extracted from a GAPS questionnaire in the last month. Moreover, only $21.4 \%$ of the respondents could specify other screening questions (mainly related to tobacco/alcohol/drug abuse) asked of adolescents recently. More senior registrars than registrars $(62.5 \%$ v. $22.1 \%, p=0.023)$ asked adolescents: 'Have you ever been physically, emotionally or sexually abused?' Also, residents who had practised for $<5$ years were more likely than older ones to ask adolescents a screening question on relationships, e.g. 'Are you dating someone?' $(p=0.045)$. Otherwise, current status, and length and sites of practice did not influence the use of standard direct questioning to screen adolescents for specific morbidities.

\section{Discussion}

This survey confirmed that adolescents are regularly seen by paediatric residents in Nigeria. General health guidance constituted the predominant AM service provided by approximately seven out of ten residents. Similarly, about half of the residents provided specific screening for morbidities. However, detailed evaluation of adolescents for medico-psycho-social dysfunction was lacking among the residents. This is not surprising because the specialty is at its infancy in the country, with limited resources available for training residents. ${ }^{[10]}$ Also, the Faculty Board of Paediatrics' requirements on duration and sites of clinical rotations in AM during residency are currently vague in Nigeria. ${ }^{[9,10]}$ There is a need for a concerted effort to improve the scope of AM services provided by paediatricians, who are the best clinicians to manage this age group, considering their developmental perspective in healthcare delivery. ${ }^{[11]}$ This would ensure the provision of comprehensive care to adolescents. Significant morbidities related to obesity, abuse, substance use, and reproductive and psychological problems have been reported among Nigerian adolescents. ${ }^{[3,6]}$ Therefore, widespread delivery of primary and secondary preventive services by all primary healthcare providers, including paediatricians, would improve the health status of Nigerian adolescents. ${ }^{[8]}$ In this survey, we found that provision of APS is grossly inadequate among residents. Only about three out of ten residents have attempted to screen adolescents for depression in the month preceding the survey, despite the fact that a majority (78.6\%) attended to adolescents at least once a week. The screening questions for specific morbidities on the GAPS questionnaire used for this study are based on the widely accepted diagnostic criteria of the Diagnostic and Statistical Manual of Mental Disorders, 4th edition (DSM-IV) and recommended checklists during history taking. ${ }^{[12]}$ Hence, unfamiliarity with the tool used in this survey could not be the reason for the low level of practice of APS found in this survey. Moreover, only a minority of participants could specify other screening questions or tools used regularly in their practice to assess adolescents. We found that the senior registrars were more likely than registrars to screen adolescents for all types of abuse. This could be due to the high level of proficiency typical of this cadre, having stayed longer in residency and possibly acquired subspecialty interests, including AM. However, the above assertion is negated by the finding that residents who had been in medical practice for $<5$ years screened adolescents for relationship issues more than those longer in practice, including senior registrars. Hence, the apparently improved performance of senior registrars in the practice of some aspects of APS may be due to their under-representation in this survey, constituting $<10 \%$ of the participants. The practice setting of the residents did not influence their provision of AM services. This is consistent with our findings in a recent national survey on AM training in Nigeria, which showed low coverage of curriculum contents pertinent to AM, limited physical facilities and professionals in all training centres nationwide. ${ }^{[10]}$ Thus, the unsatisfactory level of AM practice among residents found in this study reflects the low emphasis previously placed on the AM subspecialty in postgraduate medical education in Nigeria. The strength of this study includes its high response rate (64.4\%), which often is not attainable in physician surveys. ${ }^{[13,14]}$ Our results clearly depict the current practice of registrars in the country, and perhaps the subregion. The limited numbers of senior registrars recruited in this survey may not be representative of the current practice of this cadre of residents. Also, this suggests substantial caution in extrapolating our data to reflect the level of APS practice of specialist paediatricians in the country.

\section{Conclusion}

There is a need to restructure the ongoing practice and training of paediatrics residents in Nigeria to emphasise preventive paediatrics and other issues pertinent to adolescent care. GAPS should be developed and adopted for use in various zones of the country.

\section{References}

1. American Medical Association. Guidelines for Adolescent Preventive Services (GAPS) Recommendations Monograph. 1997:1-12. http://www.ama-assn.org (accessed 22 January 2013)

2. Nwokocha ARC. Adolescence and associated problems. In: Azubike JC Nkanginieme KEO, eds. Paediatrics and Child Health in a Tropical Region, 2nd ed. Owerri: African Educational Services, 2007:91-100.

3. Federal Ministry of Education FMOE/UNICEF. Assessment of violence against children at the basic education level in Nigeria. http://www.unicef.org/nigeria/ ng_publications_Violence_reportOAU.pdf (accessed 22 January 2013).

4. UNICEF 2013: Statistics at a glance: Nigeria. http://www.unicef.org/ infobycountry/nigeria statistics.html (accessed 23 April 2016).

5. National Strategic Framework on the Health and Development of Adolescents and Young People in Nigeria (2007-2011). Abuja: Federal Ministry of Health, 2007:1-128.

6. Nwobodo EI, Panti A. Adolescent maternal mortality in north-west Nigeria. West Afr J Med 2012;31(4):224-226.

7. Viner RM, Barker M. Young people's health: The need for action. BMJ 2005;330(7496):901-903. DOI:10.1136/bmj.330.7496.901

8. Nkanginieme KEO, Nte AR. Preventive paediatrics. In: Azubike JC, Nkanginieme KEO, eds. Paediatrics and Child Health in a Tropical Region, 2nd ed. Owerri; African Educational Services, 2007:21-27.

9. West African College of Physicians. Faculty of Paediatrics Training Curriculum. Lagos: WACP Press, 2012:1-28.

10. Abiodun MT, Omoigberale AI, Ibadin MO. Evaluation of adolescent medicine subspecialty training in Nigeria: Trainees' perspectives. East Afr Med J 2015;92(6):291-296.

11. Marks A, Fisher M, Lasker S. Adolescent medicine in pediatrics practice. J Adolesc Health Care 1990;11(2):149-153.

12. Jenkins RR. Delivery of health care to adolescents. In: Kliegman RM, Behrman RE, Jenson HB, eds. Nelson Textbook of Pediatrics. 18th ed. Philadelphia: Saunders Elsevier, 2007:111.

13. Sallis JF, Fortmann SP, Solomon DS, Farquhar JW. Increasing returns of physician surveys. Am J Public Health 1984;74(9):1043.

14. Nicholls $K$, Chapman $K$, Shaw $T$, et al. Enhancing response rates in physician surveys: The limited utility of electronic options. Health Serv Res 2011;46(5):1675-1682. DOI:10.1111/j.1475-6773.2011.01261 